\title{
Workshops and data collection: Ways to embed clinical complexity in learning events
}

\author{
Anna Treloar ${ }^{1} \cdot$ Penelope Little ${ }^{2} \cdot$ Teresa Stone $^{3} \cdot$ Margaret McMillan $^{4}$ \\ 1,2,3,4 School of Nursing and Midwifery, University of Newcastle, Australia
}

\section{ABSTRACT}

Objectives: i) To explicate the constructivist nature of workshop processes to assist participants in the development of stories that are meaningful for educational purposes; ii) to position problem/practice-based learning (PBL) activities within constructivist theory. iii) to explore the construction and potential value of clinical anecdotes told by nurses to others new to the discipline of mental health nursing.

Methods: Three workshops were held, both to collect stories, and to record insights from two groups of experienced mental health nurses, and one group of undergraduates close to registration, about how the stories could be interpreted and the purpose of telling selected stories to newcomers to the discipline.

Case study methodology was used for exploration of these stories because this is a flexible approach often used in educational research. It is particularly suitable where the question is "how?" or "why?" and the components of a case study are people, things, events, contexts and relationships, components which are suitable for analysis of stories about mental health nursing.

Results: Stories ( $n=100$ ) were collected directly from mental health nurses during and after the workshops as well as a few previously published sources; these were analysed for their fitness for educational purposes.

The stories fell into three main groups, the first at the surface level, dealing with the history of mental health nursing and providing examples of mental health nurse humour; the middle level offering a variety of insights into daily work in mental health nursing whether in the hospital, the community, the prison or other setting, and the deepest level stories showed the attitudes and skills developed by experienced mental health nurses.

Conclusions: Thoughtful structuring and facilitation of the workshops was critical to the data collection process. The clinical anecdotes collected capture much which is not contained in textbooks and those depicting deeper appreciation of the specialty, better equip students to enter the real world of mental health nursing, where not everything is predictable and orderly, and where "inspired creativity" is often required and shown to manage difficult situations.

The analysis of storylines demonstrates that the manner in which one conceptualizes practice has the potential to impact on learning outcomes for a new generation of mental health nurses who work in novel contexts of practice.

Keywords: Workshops in research and learning, Mental health education, Story lines for learning 


\section{BACKGROUND}

Mental health nurses tell stories in both the formal classroom or lecture setting and in the workplace. Many are told to undergraduates and to new recruits. The purpose of the storytelling and the possible interpretations and messages taken away by the listeners has not previously been explored. The contribution that the stories make to enhanced practice and education had not been fully explicated. Case study methodology was selected as the most useful design for the research (Treloar, Stone, McMillan \& Flakus, 2015).

There are a number of ways in which the stories for this study could have been collected but this paper describes the use of workshops to begin the process - an underused and creative way to collect rich data.

\section{INTRODUCTION}

Miley et al. (2012) define case study as an "in-depth examination of a specific circumstance" (p.28) so that it may focus on an individual, a community, an organisation, a practice (such as storytelling) or an event. It is useful where the question is "How?" or "Why?" (Yin, 2009) and the case may be a student, a classroom, a committee, a program but not a problem, a relationship or a theme. It has "a unique life" (Stake, 1995, p.133). Case study has been used frequently in educational research and allows sufficient "organic flexibility" (Snyder, 2012, p.19) for this exploratory question. One of its purposes is to make the familiar seem strange so that attention can be drawn to it (Watts, 2007).

The case study was the phenomenon of storytelling by nurses to others in a mental health setting and each story became a case for cross case analysis and conclusions (Yin, 2004). Because not much is known about the purpose of telling these stories and because case study is useful for "what?" questions, it was appropriate for this study. PBL (Problem Based Learning) scenarios are constructed with a specific purpose in mind (Wood, 2003); even vignettes used in educating families of children with mental illness are constructed carefully to suit their specific purpose (Lapatin et al., 2012), while sociologists use scenarios in what they call constructive controversy case study to generate discussion and deeper understanding of sociological thinking (Bird \& Erickson, 2010). Although case study is a bounded system, it is not bounded by geography. Tripp (1994) defines the components of a case study as people, things, events, context and relationships and these five components are present in any story about mental health nursing practice. Case study is useful where a deeper understanding of a particular practice is required and may describe or explain; it does not seek to generalise though hypotheses may be formed. Stake (2005) stresses the opportunity to learn from the case study as being one of its main aims while Lodge (2002) comments that the "experiment" itself partly determines the direction and content of the researcher's thoughts. If, as Stake (1995) says, the case can be a classroom, then stories are part of the curriculum in this particular classroom where mental health nursing is being taught, but we do not know what the reason is for their use in the classroom. The experiences of individuals and the contexts of the action are important (Darke, Shanks \& Broadbent, 1998). There is going to be some "tension between theoretical integrity and utility" (Thorne, 2008, p.34).

The aim of the workshop within this case study on 'storytelling' by experienced mental health nurses was to compile a resource of exemplars. The nature and extent of use of stories in curriculum implementation is influenced by the curriculum design (Carroll, 2010; Scutt, 2013; Treloar, McMillan \& Stone, 2015) 
Both the use of the workshop within this study design and the use of stories as an educational tool for those new to or more experienced in an area such as mental health nursing is 'constructivist' in nature.

The theory underpinning constructivism derives from psychology and philosophical views on how we come to understand or know (Savery \& Duffy, 1995). It provides an explanation of how people might acquire knowledge and learn. The overarching constructivist learning principle emphasizes that learning is an active process in which students construct, reconstruct or elaborate their knowledge (Dolmans, De Grave, Wolfhagen, \& Van Der Vleuten 2005; Savery \& Duffy, 1995, p.1) list three aspects of constructivism:

\section{The core concept of constructivism is that} understanding is in interactions with the environment. We cannot talk about what is learned separately from how it is learned, what is understood is a function of the content, the context, the activity and goals of the learner,

2. Cognitive conflict or puzzlement is the stimulus for learning and determines the organization and nature of what is learned.

3. Knowledge evolves through discussion, collaboration and evaluation of the viability of individual understandings and the social environment is critical to the development of individual understanding and development of knowledge.

Constructivism is applicable to nurse education given that it suggests that people construct knowledge and meaning from their experiences (perspectives, values, attitudes) and their understandings of these to the learning situation and all learning takes places in a context (Nyback, 2013). It has been argued that constructivism supports the education of nurses by improving critical thinking skills to enable nurses to work with complex patients in a rapidly changing environment (Candela, Dalley, \& Benzel-Lindley, 2006). Teaching within a constructivist framework requires educators to focus on making connections between facts and foster new understanding, adapting their approach according to student responses to encourage students to analyze, interpret, and predict information (Nyback, 2013).

Constructivism is not a specific pedagogy but does assist with the design of educational experiences. Problem/ practice-based learning as a philosophy along with methods common to PBL, fits within a constructivist paradigm. Research around constructivist teaching techniques demonstrates some support while other reports are less positive about learning outcomes emerging from the use of PBL techniques.

The aim of the stories emerging from the specially constructed workshops was to provide stimuli for mental health nurses to 'review' the complex environment of mental health care from multiple perspectives. Through the workshop processes, interactions among members of the group increases the potential to tell their stories in a way that enhanced transfer of knowledge and insights. The educative purpose of the stories is to enhance the learners' engagement with the discipline. The greater the flexibility with which learners can deal with new information the more thoroughly they are prepared for future learning (Dolmans et al., 2005). Designing effective stimulus material is the key to successful learning activities; it is essential that students learn by analyzing and resolving representative situations and problems (Dochy, 2003). If stimuli are too well-structured, too close ended or too simple, students are not challenged to actively engage and construct new learning (Dolmans et al., 2005). Students become more confident and competent as a result of working with learning instruments based on real life, i.e. 
dealing with authentic problems or complex situations (Baxter \& Shavelson, 1994; Birenbaum, 1996).

\section{METHODOLOGY}

For nurse researchers using the qualitative paradigm, meaning, rather than truth, is what is sought. Reality is regarded as not only subjective but as essentially the construction of individuals interacting in a social environment. The researcher's interpretation of this is yet another construction. Narrative analysis within the ethnographic paradigm examines the stories of participants from data collected during interviews. The researcher recognises that the tellers of the story select the components to convey the meaning which they want the listener to derive from the telling of the story. The teller conveys meaning not truth and the truth is of the teller's experience which cannot be objective or externalised (Bailey \& Tilley, 2002).

Stories for this project were collected from different nurses who have varying work experiences and different specialisations, from recent practice, from many years ago or even have been told to the teller by somebody else.

\section{The workshop}

The development of the workshop in this case study was based on the same constructivist principles aligned to PBL. It was designed for the following purposes:

1. To collect narratives from experienced nurses in order to interrogate the purpose of their use in practice and education.

2. To determine criteria for analysis of the stories collected to more fully appreciate the educative value and therapeutic intent for neophyte nurses
3. To provide an opportunity for Mental Health Nurses to reflect on the role of storytelling in the orientation of new graduates

Little an advocate for PBL has used the following strategies and underlying principles within a template for the design of workshop activities in translational and educational research conducted with colleagues over three decades. The outcomes have resulted in policy and practice across many domains such as around the use of professional standards (McMillan et al, 1999), the determination of the scope of contemporary nursing practice (McMillan et al, 1997), curriculum design and renewal (McMillan \& Little, 2016), and the quality use of medications in nursing (Baker et al, 1997). The basic design used can be broken down into a number of steps:

1. Formulate desired outcomes and design activities to achieve these

Rationale: There is a need to be clear about what, from your perspective, you want the workshop to achieve. It is also important to consider participants' desired outcomes/ expectations and any misalignment between the two.

2. Ask the participants to acknowledge/share their different levels of experience and expertise at the beginning of the workshop.

Rationale: The workshop presenter/moderator is able to contextualize the workshop and use the experiencel expertise of the participants to inform the workshop. This also signals to participants that they are active partners in the process and assesses the range of competence within the group.

3. Engage the participants in thinking, doing and communicating as well as listening.

Rationale: This approach is what distinguishes a workshop from presentations and demonstrations. 
Participants need the opportunity to test out and apply understanding.

4. Recognize that participants hold beliefs and perceptions that are difficult to challenge even with evidence contrary to their views.

Rationale: Activities need to be directed towards participants acknowledging dissonance.

5. Utilize intuitive activities that are effective in interrogating participants' ideas and beliefs

Rationale: Participants engaging in activities without knowing the purpose tend to respond from their own belief system rather than what they think is expected.

6. Activities need to address process as well as content: Discuss content that is central to the activity and then process - their experience of the activity, the intent and design of the activity.

Rationale: Participants will often readily engage with the content (knowledge/expertise) but not with their own experience of the process as a participant (learner). They may focus on content because it is safer and be unaware of other processes such as learning styles, group membership, belief systems.

7. Most participants usually prefer small over large group activities

Rationale: It is safer for participants to test out ideas in a small group rather than reveal their thoughts to the presenter and the large group.

8. Activities need to include one carefully controlled opportunity for input on a range of views from a range of contributors in order to cater for some participants' demand to be heard by members of the large group. Rationale: Participants who have an agenda, high status within the group or expertise are given an opportunity to contribute to the large group.
9. Use activities that maximise opportunities for individual contributions.

Rationale: If the group is a consultative reference group, it is essential to capture the thoughts of individuals, not just report on 'group think'.

10. Every workshop is context specific and therefore must be individually tailored.

Rationale: Every audience is context specific and therefore needs to be individually tailored.

11. Be flexible - be prepared to alter a plan if participants are not engaged with the process.

\section{Specific strategies}

- Begin promptly, focus on objectives, hook interest on content.

- Aim your initial remarks at the immediate concerns of your listeners, for example their concerns about the topic or workload.

- Start the workshop by expressing appreciation of participants' expertise, experience and achievements. This can be achieved in a 'two-minute discussion' session across sub-groups of two or three. Feedback on expertise/experience can be achieved through a show of hands'.

- Use a mix of individuals (small groups can differ in size $-2,3,7)$ and whole group activities

- Establish details of the current context i.e. about clinical reasoning models, use of simulations

- Identify and list issues/concerns (open brainstorming with the whole group, depending on size). This acknowledges participants' agendas and also allows for reference to these in later discussions. 
- Complete 2,3,4 above before presenting any data, because this approach is more conducive to careful consideration of any information presented.

- Cause the participants to disclose their own views where possible before presenting information.

- Include activities that provide opportunities for discussion/debrief/critique of presentations/stimulus material etc.

- Ensure activities are not complex in themselves.

\section{Range of participants}

The participants for the first workshop were all experienced in mental health nursing: A Level B academic, a Nurse Manager, a Clinical Nurse Consultant, and 3 New South Wales (NSW) Registered Nurses (RNs) Year 8 and thereafter.

\section{Recruitment}

Ethics approval was gained from the University of Newcastle's Human Research Ethics Committee and after a small pilot study subsequently a larger group of mental health nurses in the Local Health District were sent the documents (poster, participant information and consent) by email with an invitation to attend a workshop held at the School of Nursing and Midwifery. Senior academics were also advised of the workshop and requested to inform anybody who might be interested of the project. In total 37 (plus all staff at the School of Nursing and Midwifery at the University of Newcastle) were emailed; 26 replied; and 19 actually sent stories or attended a workshop without replying.

From this second invitation a number of mental health nurses expressed their intention to attend either as a result of a direct personal invitation received or because they had heard about the workshop from another person. Once again those who came were experienced mental health nurses. Two had attended the pilot workshop and agreed to mark their stories with "P" to indicate prior knowledge of the workshop process. This workshop was conducted by an external facilitator with extensive experience in education and practice based learning and by one of the researchers who was the principal investigator but not the $\mathrm{PhD}$ candidate. The candidate took no part beyond making detailed notes. The workshop lasted for five hours.

The principal investigator's role centred on recording strategy, reflections on processes and interpretation of interactions. For both the small pilot workshop and the main workshop which used the framework the candidate was "a silent observer". Participants knew that she was conducting the study as part of doctoral studies but beyond that the candidate did not join in the storytelling or the associated discussions. She took notes in longhand and on the same day as the workshop took place she went over her notes to make sure they were legible and comprehensible and that they were a good record of what happened.

\section{DISCUSSION}

The three workshops were an effective means of harvesting a variety of stories $(n=24-5$ from the pilot workshop, 12 from the main workshop and 7 from the student workshop) from participants. These were not the well-structured, close ended simple stories Dolmans et al. (2005) stated were not effective for constructive and contextual learning. Instead they were complex, open to multiple interpretations and based on real life encounters that nurses working in mental health had themselves found confronting, memorable or challenging. 
While collecting the stories we were always mindful that the "surface" message might not be the intended or the final meaning. We were also mindful that the most useful stories for teaching often contain several meanings or else layers of meanings. Students need a range of stimulus material if they are to effectively construct meaning (Dolmans et al., 2005).The workshop design drew out a variety of diverse stories from participants. Participant selection was also important in this regard as context can be a crucial moderator of choices in care. Little provides a range of questions that facilitators can draw upon in a learning activity. These questions can be used when discussing a story such as the following

I remember my angst whilst working with a 16-year-old girl who had a history of violent assault and who would frequently present to counselling sessions with quite serious self-harm as well as suicidal ideation with plan and intent. It was challenging to try to determine the level of risk and the most appropriate response to ensure safety and maintain a therapeutic rapport.

In sessions, this young woman would often talk about her wish to die. She could not visualise any future for herself. However, on one occasion when I asked about future plans and if she had any desire to travel, she spoke about wanting to go to Spain to go running with the bulls. Although a high-risk adventure, to me it was a ray of hope as she was giving some consideration to her future and had a plan for her early adult years. She is now 21 years, still hasn't been to Spain but is attending University and although there continues to be issues with self-harm and suicidality she is still making future plans.

The following questions (Little, in Conway and McMillan 2010, 359-360) provide useful stimuli for learning events.

\section{Situation/analysis or decision-making}

- What information do I have?

-What further information do I need?

- What options/alternatives do I have?

- What should I prioritise?

-What action/s should I take?

- Why?

- Can I justify this action (lawfully, ethically, effectively, theoretically)?

\section{The learning process}

- What do I already know?

- How do I know it?

- What do I need to know?

- How will I know I know?

\section{Perceptions}

-What are my feelings?

-What are my beliefs about the situation?

- What are my assumptions?

- How have I derived these beliefs/assumptions?

- How do my feelings/beliefs

- affect my interpretation?

- affect my response?

- relate to espoused professional values?

-Why do I hold this belief/assumption?

- What are alternative beliefs/assumptions?

When some of the stories were presented to a small group of Third Year BN students in a workshop which took place after the main story-collecting workshop, their responses and interpretations varied widely. One of the stories used in this student workshop follows:

In the Child and Adolescent Unit working with a psychotic young boy with a significant trauma history: I had a good relationship with him. He was walking up 
and down the hallway while a group of nurses stood nearby.

In attempting to engage with him I asked him a few questions. At one point I asked him did he want a hug to which he said yes. We then hugged for a brief time.

And then continued what we were doing.

Student A saw the issue here as being one of boundaries, saying that she was "not really sure where the boundary is", and that whereas in aged care she could "spend the day kissing and hugging older people", in adolescent nursing she was not sure if that was appropriate, adding that as a student it is difficult to gauge appropriateness. She saw the boy as "just going about his day" and said if an educator told her this story she would ask if hugs were offered to everybody or just exclusively to one person, concluding that she would not copy this behaviour. She said this story would not be appropriate for undergraduate nursing students, as some are only 19 year old girls and "this person could take it as meaning more than it does".

Student B surmised that the young patient may have had the "feeling of being protected which you get from a hug" and said the interaction was "possibly therapeutic". She said it would depend on the relationship between the staff member and the client whether or not it was suitable for telling to students, but felt there was "history there" so that it was "appropriate to say, 'Do you want a hug?".

Student $\mathrm{C}$ commented that she knew that mental health nursing “is different and it depends on how long they've known the patient for" adding that she would "baulk if there was a traumatic history". She felt it was suitable for use with students as it "would create discussion".

The discussion stimulated students sharing different perspectives about the stories and the reflection and elaboration of learning this provokes increases depth of learning and retention.

\section{CONCLUSION}

Stories were collected directly from mental health nurses and also from a few previously published sources; these were analysed and their fitness for educational purposes explored.

The stories fell into three main groups, the first at the surface level, dealing with the history of mental health nursing and providing examples of mental health nurse humour; the middle level offering a variety of insights into daily work in mental health nursing whether in the hospital, the community, the prison or other setting, and the deepest level stories showed the attitudes and skills developed by experienced mental health nurses. Without the workshops, collecting these stories might have been much more challenging and without the framework for discussion their educational value might be much less apparent.

\section{REFERENCES}

Baker, H., McMillan, M., Wade, A. \& Linsley, R. (1997). Indicators of the Quality Use of Medications by Nurses in Australia. The Pharmaceutical Education Program. Pharmaceutical and Rational Use of Medicines, Canberra

Bailey, P. \& Tilley, S. (2002). Storytelling and the interpretation of meaning in qualitative research. Journal of Advanced Nursing, 38 (6), 574-583.

Baxter, G. P., \& Shavelson, R. J. (1994). Science performance assessments: Benchmarks and surrogates. International Journal of Educational Research, 21(3), 279-298.

Bird, S. \& Erickson, K. (2010). A constructive controversy approach to "case studies". Teaching Sociology, 38 (2), 119131. Doi: 10.1177/0092055X10364014.

Birenbaum, M. (1996). Assessment 2000: towards a pluralistic approach to assessment. In M. Birenbaum \& F. J. R. C. Dochy (Eds.), Alternatives in assessment of achievements, learning processes and prior knowledge. Evaluation in 
education and human services (pp. 3-29). Boston, MA: Kluwer Academic Publishers.

Candela, L., Dalley, K., \& Benzel-Lindley, J. (2006). A case for learning-centered curricula. Journal of Nursing Education, 45(2), 59-66.

Carroll, V. S. (2010). "Once upon a time..."-narrative in nursing. Journal of Neuroscience Nursing, 42(5), 235-236.

Darke, P., Shanks, G. \& Broadbent, M. (1998). Successfully completing case study research: combining rigour, relevance and pragmatism. Information Systems Journal, 8, 273-289.

Dochy, F., Segers, M., Van den Bossche, P., \& Gijbels, D. (2003). Effects of problem-based learning: a meta-analysis. Learning and Instruction, 13, 533-568.

Dolmans, D. H., De Grave, W., Wolfhagen, I. H., \& Van Der Vleuten, C. P. (2005). Problem-based learning: Future challenges for educational practice and research. Medical Education, 39 (7), 732-741.

Lapatin, S., Goncalves, M., Nillni, A., Chavez, L., Quinn, R....\& Alegria, M. (2012). Lessons from the use of vignettes in the study of mental health service disparities. Health Services Research, 47 (3), Part II 1345-1362. Doi: 10.1111/j.14756773.2011.01360.x

Little, P in Conway, J. \& McMillan, M. (2010) Connecting Clinical and Theoretical Knowledge for practice. Contexts of Nursing 3e, Daly, J. Speedy, S. \& Jackson, D. Churchill Livingstone, $3^{\text {rd }}$ edition. Sydney

Lodge, D. (2002). David Lodge Thinks, New York: Penguin.

McMillan, M., Keatinge, D., Bellchambers, H., Bujack, E., Harmon, C., Schultz, L., Sharkey, R., \& Baker, H. (1998/99) The Development of Guidelines for Registered and Enrolled Nurses regarding the Boundaries of Professional Practice. New South Wales Nurses' Registration Board

McMillan, M, Little, P, Baker, H, Bujack, E, Johnston, R. (1997) Scope of Nursing Practice. Queensland Nursing Council, Brisbane, Australia

McMillan, M. and Little, P. (2016) NSW Institute of Psychiatry: The Development of Philosophy and methodology for post-graduate programs. Sydney

Miley, F., Cram, B., Griffin, A., Kennelly, R., McCormack, C. \& Read, A. (2012). Using stories in teaching. Milperra
Australia: HERDSA.

Nyback, M. H. (2013). A constructivist approach to teaching and learning at the degree programme in nursing at Novia University of applied sciences. Retrieved from Finland: https://www.novia.fi/dmsdocument/29

Savery, J. R., \& Duffy, T. M. (1995). Problem based learning: An instructional model and its constructivist framework. Educational technology, 35(5), 31-38.

Scutt, C., \& Hobson, J. (2013). The stories we need: anthropology, philosophy, narrative and higher education research. Higher Education Research and Development, 32 (1), 17-29. doi:10.1080/07294360.2012.751088,

Snyder, C. (2012). A case study of a case study: Analysis of a robust qualitative research methodology. The Qualitative Report 17, (article 26), 1-21.

Stake, R. (1995). The Art of Case Study Research. Thousand Oaks CA: Sage.

Stake, R. (2005). Qualitative Case Studies. In N. Denzin \& Y. Lincoln (Eds.). The Sage Handbook of Qualitative Research (3rd ed.) (pp. 443-466). Thousand Oaks CA: Sage.

Thorne, S. (2008). Interpretive Description. Walnut Creek, CA: Left Coast Press.

Treloar , A., Stone, T., McMillan, M. \& Flakus, K. (2015). A narrative in search of a methodology. Perspectives in Psychiatric Care, 51 (3), 202-210. Doi: 10.1111/ppc.12081.

Treloar, A., McMillan, M. \& Stone, T. (2015). Authenticity: A critical element in the use of clinical anecdotes as stimulus material for undergraduates in mental health nursing. Journal of Problem-Based Learning, 2 (1), 25-33.

Tripp, D. (1994). Case study: Creating the data. In J. Smyth (Ed.), Conference proceedings for the mini-conference, Qualitative approaches in education research (pp.27-42). Adelaide Australia: Flinders University.

Watts, M. (2007). They have tied me to a stake: reflections on the art of case study research. Qualitative Inquiry, 13204. Doi: $10.1177 / 1077800406295628$.

Wood, D. (2003). ABC of learning and teaching in medicine: Problem based learning. British Medical Journal, 3268 February 328-330.

Yin, R. (2004). The case study anthology. Thousand Oaks CA: Sage. 
Yin, R. (2009). Case study research: Design and methods. 4th ed. Thousand Oaks CA: Sage. 